\title{
Does Practice Enhance Adaptability? The Role of Personality Trait, Supervisor Behavior, and Career Development Training
}

\author{
Mei Mei*, Fu Yang and Mingfeng Tang \\ School of Business Administration, Southwestern University of Finance and Economics, Chengdu, China
}

Drawing upon career construction theory, we examined the mediating effect of deliberate practice (DP) on career adaptability (CA) and the effects of learning goal orientation (LGO) and supervisor incompetence accusations (SIA) as well as career development training (CDT) on DP. Using data collected from 204 Chinese PhD students in three waves over a period of 2 months, we found that individuals who were inclined to learn new skills and obtain new knowledge were more likely to deliberately practice professional activities in their fields. When a PhD student's professional competence was questioned by his or

OPEN ACCESS

Edited by:

David Bueno,

University of Barcelona, Spain

Reviewed by:

Rebekah L. Latyton,

University of North Carolina at

Chapel Hill, United States

Deb Agnew,

Flinders University, Australia

*Correspondence:

Mei Mei

may5131@163.com

Specialty section:

This article was submitted to Educational Psychology, a section of the journal

Frontiers in Psychology

Received: 14 August 2020 Accepted: 20 October 2020 Published: 04 February 2021

Citation:

Mei M, Yang F and Tang M (2021) Does Practice Enhance Adaptability?

The Role of Personality Trait,

Supervisor Behavior, and Career

Development Training.

Front. Psychol. 11:594791.

doi: 10.3389/fpsyg.2020.594791 her supervisor, the student was more prone to negative emotions and would reduce his or her effort in the development of expertise. CDT - contrary to expectations - negatively predicted DP of professional activities. One possible reason is that the participants in this study have strong autonomy so that those who really struggling are participating in training and seeking help and those who with strong professional abilities are not accessing training programs. Moreover, results showed that DP of professional activities significantly promoted PhD students to adapt to their academic circumstances. Implications for careerrelated practice within the academic domain are provided.

Keywords: learning goal orientation, incompetence accusations, career training, deliberate practice, career adaptability, early career scientists

\section{INTRODUCTION}

Career adaptability (CA), a central construct of career construction theory (Savickas, 2002; Savickas et al., 2009), represents individuals' psychosocial resources that help one to fit environmental change (Savickas, 1997). Indeed, CA has been shown empirically to be a significant and universally valid factor that enables individuals to facilitate psychological adjustment and achieve adaptation goals (e.g., Guan et al., 2013; Fiori et al., 2015; Hirschi et al., 2015; Ghosh et al., 2019; Urbanaviciute et al., 2019), thus emerging vocational research on career construction theory has started to explore the drivers of CA (Coetzee and Harry, 2013; Zacher, 2014; Shin and Lee, 2016; Autin et al., 2017; Obschonka et al., 2018; Pajic et al., 2018).

Young scholars are a group that typically faces high levels of job insecurity and stress (Kinman, 2001; Levecque et al., 2017). The increased workloads and continuous change in academic research make universities increasingly stressful environments, resulting in a number of reports of mental health concerns such as depression and anxiety among $\mathrm{PhD}$ students (Levecque et al., 2017). In order to successfully adapt to occupational stressors and strains, 
PhD students need to be equipped with CA that could help them cope with current and anticipated occupational challenges. CA is considered as an effective human capital that enables individuals to reduce work stress (Johnston et al., 2013) and to form successful adaptation (Negru-Subtirica and Pop, 2016). In this respect, we emphasize the importance of CA in the academic context and focus on exploring the antecedents and underlying mechanisms of the development of CA.

Career construction theory and the ancillary research suggest that individuals who are open to new experiences tend to flexibly respond and adjust to career environments (Savickas, 2013; Tolentino et al., 2014). In order to explore the role of individual characteristics in predicting one's adaptability, we focus on learning goal orientation (LGO), a relatively stable personality trait that refers to the tendency to develop competence and master new ideas (Dweck, 1986; Tolentino et al., 2014). In terms of work context, the influence of supervisor is one of the most frequently examined work characteristics (Levecque et al., 2017; Lan and Chen, 2020). Accusations of incompetence from $\mathrm{PhD}$ supervisors are negative events in which supervisors call into question the research abilities of the students, which may affect students' negative emotions. Therefore, we attend to the role of supervisor incompetence accusations (SIAs) in affecting PhD students' self-directed learning process. Moreover, from an organizational perspective, we focus on a supportive organizational environment in which organizations provide career guidance to individuals. As CA is arguably a dynamic and changeable construct rather than a relatively stable personal trait (Savickas and Porfeli, 2012), scholars suggested that the impact of career intervention should be considered in developing adaptability resources (Verbruggen and Sels, 2008). In the current research, we seek to examine career development training (CDT) as a potential antecedent of CA so as to see whether career interventions are effective for $\mathrm{PhD}$ students.

For PhD students, the primary tasks for their roles as students and young scholars are their academic research. Undoubtedly, the mastery of academic skills will affect $\mathrm{PhD}$ students' career outcomes. In this respect, activities in terms of professional competence improvement may be important mechanisms through which $\mathrm{PhD}$ students could gain adaptability resources. Deliberate practice (DP) refers to a series of selfdirected and repetitive activities (e.g., professional reading, mental simulation, and feedback seeking) that are performed in one's area of expertise (Ericsson et al., 1993; Dunn and Shriner, 1999; Unger et al., 2009). In the present study, we further examine a mediating role of DP in the academic field and argue that $\mathrm{PhD}$ students may develop their CA through deliberately performing these professional activities.

\section{THEORETICAL BACKGROUND AND HYPOTHESIS DEVELOPMENT}

\section{Career Adaptability}

Career adaptability is defined as the "readiness to cope with the predictable tasks of preparing for and participating in the work role and with the unpredictable adjustments prompted by changes in work and working conditions" (Savickas, 1997, p. 254). It is viewed as a multidimensional concept organized into four types of psychological resources: concern, control, curiosity, and confidence (Savickas and Porfeli, 2012). These four constructs reflect individuals' adaptive coping capacities that individuals use to respond to environmental change, which is affected by both individuals and the environment (Savickas, 1997; Savickas et al., 2009; Savickas and Porfeli, 2012). To date, some important strides have been made in identifying the influence of individual and contextual factors on CA (e.g., Guo et al., 2014; Hou et al., 2014; Tian and Fan, 2014; Xu and Yu, 2019). However, empirical evidence on the role of contextual factors in CA research is still somewhat scarce (Autin et al., 2017; Pajic et al., 2018). Accordingly, the present study attempts to explore both individual and contextual predictors of $\mathrm{CA}$ in the academic context.

\section{Deliberate Practice}

Deliberate practice refers to a series of self-directed, effortful, and repetitive activities that have been specially designed to achieve expertise (Ericsson et al., 1993). As an essential learning behavior to attain an expert level of performance, DP has been emphasized and explored in various domains such as music (Ericsson et al., 1993), chess (Charness et al., 2005), sports (Hodges et al., 2006), software design (Sonnentag et al., 2006), and entrepreneurship (Unger et al., 2009; Keith et al., 2016; Ranabahu and Barrett, 2019). However, when it comes to scientific research, the role of DP to improve the current level of expert performance is neglected.

Deliberate practice consists of a wide range of practice and learning activities that are performed regularly. These regular, continuous, proactive learning activities facilitate remarkable adaptation across different domains in a changing environment (Ericsson et al., 1993; Ericsson and Lehmann, 1996). In previous studies, scholars have identified different forms of DP activities, for example, mental simulation, seeking feedback, consulting experts, or colleagues, etc. (Sonnentag and Kleine, 2000; Unger et al., 2009). When a specific activity is considered as DP, it needs to meet at least the following conditions: (a) the activity is performed on a regular basis; (b) the activity is designed for performance improvement; and (c) the activity is undertaken with the motive to improve and goes beyond the task requirements (Sonnentag and Kleine, 2000; Ericsson, 2006; Unger et al., 2009). Based on the previous research, the present study aims to examine the role of DP in scientific research field.

\section{Learning Goal Orientation and Deliberate Practice}

According to Savickas and Porfeli (2012), individual differences serve as important antecedents in the career construction process. In this respect, we first focus on LGO, a dispositional personality that implies great willingness and persistence to try hard in the acquisition of knowledge and skills (Dweck, 1986). LGO is strongly associated with learning activities (Baek-Kyoo et al, 2013). Due to the mastery-oriented response pattern inherent in LGO (Dweck, 1986); individuals who are learning-goal-oriented 
are likely to engage in adaptive behaviors to improve competencies (Tolentino et al., 2014). In this respect, learning-goal oriented individuals tend to initiate DP including a series of adaptive behaviors designed to improve a person's expert performance (Ericsson et al., 1993). Moreover, to deliberately train oneself to reach beyond one's current level of performance, repeated attempts are required (Ericsson et al., 2007). LGO implies a high level of persistence in effort under difficult conditions (Dweck, 1986; Button et al., 1996), enabling individuals to endure massive amounts of practice on the specific activities. Thus, we hypothesize the following:

Hypothesis 1: LGO is positively related to DP.

\section{Supervisor Incompetence Accusations and Deliberate Practice}

Incompetence accusations are "negative events in which fellow team members call into question the capability or performance of focal team members" (Chattopadhyay et al., 2010, p. 812). Consistent with the important role of leadership in work settings, the style of supervision also holds great promise for application in the academic context. Negative supervisor behaviors or events are likely to trigger subordinates' negative emotions, whereby subordinates who received negative information from supervisors tend to produce negative behaviors toward their job (Hon et al., 2013). Because professional expertise is important for individuals to achieve legitimization of their profession and to get higher status in society (Chattopadhyay et al., 2010), people strive for positive performance assessment and recognitions of their professional competence. Incompetence accusations from $\mathrm{PhD}$ supervisors could be viewed as fairly negative information on academic tasks. It signals that a supervisor is dissatisfied with a $\mathrm{PhD}$ student's professional ability. When $\mathrm{PhD}$ students perceive high levels of incompetence accusations, negative emotions, and pressure from such excessive criticism may reduce their efforts in accomplishing routine tasks (Hon et al., 2013). Therefore, PhD students would be discouraged to invest efforts in active learning when they receive serious incompetence accusations. Taken together, it is hypothesized:

Hypothesis 2: SIA is negatively related to DP.

\section{Career Development Training and Deliberate Practice}

In the present study, we focus on CDT, as a key predictor of $\mathrm{DP}$, referring to the experience in participating in multiple career activities including career interventions, career courses, and career counseling. It needs to be clarified that careerrelated training and DP have different contents. The purpose of career training is usually to improve vocational related skills. For example, through job interview role play, individuals can improve their career problem-solving abilities (Koen et al., 2012). In contrast, DP activities are conducted to improve one's professional abilities (Ericsson et al., 1993). We theorize that individuals with CDT are likely to be encouraged to invest effort in DP. For example, career interventions usually include methods and task assignments such as career exploration, networking events, and role-playing exercises (Brown et al., 2003; Akkermans et al., 2014). Under the guidance of such experiences, individuals have chances to put their efforts into competence development practice after the interventions. Additionally, career courses can produce positive career outputs such as cognitive development, positive career-related thoughts, and career decision-making skills (Hansen et al., 2016). With the increased career abilities, one can better perform DP activities in his/ her profession. Moreover, career counseling is found to be effective to help clients to improve their career self-directedness (Verbruggen and Sels, 2008), propelling individuals to engage in proactive learning activities. Thus, we hypothesize:

\section{Hypothesis 3: CDT is positively related to DP.}

\section{The Mediating Role of Deliberate Practice}

As mentioned before, CA is arguably a malleable construct (Savickas, 1997; Savickas and Porfeli, 2012), suggesting that it may be developed through a series of training activities. DP involves a series of activities designed to improve the current level of professional performance (Ericsson et al., 1993), helps one update existing knowledge and better adapt to changing environments (Unger et al., 2009). These continuous and proactive learning activities have been examined to facilitate remarkable adaptation across different domains (e.g., Ericsson et al., 1993; Dunn and Shriner, 1999). Accordingly, we propose that DP is practical in the acquisition of essential CA resources in the career development process. For example, when individuals initiate learning activities to train themselves by constant feedback seeking, consulting, and professional reading, they may get access to available information about their professional strengths and weaknesses. This may lead them to look ahead to their future and better prepare for possible career opportunities, resulting in improved CA. Taken together, we propose that:

Hypothesis 4: DP is positively related to CA.

Based on the above argument, we hypothesize a mediating role of DP in transmitting the effects of LGO, SIA, and CDT on CA.

Hypothesis 5a: DP mediates the relationship between LGO and CA.

Hypothesis 5b: DP mediates the relationship between SIA and CA.

Hypothesis 5c: DP mediates the relationship between CDT and CA.

\section{The Present Study}

This study aims to make four primary contributions. First, drawing on career construction theory, our work extends the literature on the relationship between career adaptivity and CA. In career construction theory, adaptivity involves individual characteristics or the willingness to change (Savickas and Porfeli, 2012). We thus explore career adaptivity in terms of LGO among early career scientists, a group that especially needs frequent learning, and argue that LGO is an important 
antecedent of CA. Second, the investigation of incompetence accusations answered an expressed call in career construction research that the environment factors need to be taken into consideration in the analysis of CA (Savickas, 1997; Savickas et al., 2009; Savickas and Porfeli, 2012). Third, we aim to extend the literature on career-related training using a non-traditional sample of $\mathrm{PhD}$ students that are often overlooked in career development research. Finally, we offer a theoretical and empirical account of a self-learning factor (i.e., DP) as key mediating mechanisms, providing a better understanding of the role of self-directed learning in transmitting the effects of LGO, SIA, and CDT on CA. Figure 1 depicts the theoretical model of this study.

\section{MATERIALS AND METHODS}

\section{Participants and Procedures}

Our participants were from two public universities in Southwest China. This research has been approved by the Academic Ethics Committee of Southwestern University of Finance and Economics. We collected research data in three separate waves with each wave about 1 month apart. In wave 1 , participants were asked to complete measures of control variables (i.e., age, gender, grade, major, and graduation requirements) and independent variables (i.e., LGO, SIA, and CDT). A total of 277 participants completed the questionnaires in wave 1 (60\% response rate). One month later, participants who completed wave 1 were asked to complete measures of the mediating variable (i.e., DP). In this round, we received a total of 239 completed questionnaires $(86.3 \%$ response rate). Finally, 1 month after wave 2, participants who completed wave 1 and wave 2 were asked to evaluate their CA, resulting in 204 completed questionnaires (85.4\% response rate).

We conducted the surveys in the two universities mainly using paper-based surveys, supplemented by some online responses. The paper and electronic questionnaires accounted for 72.6 and $27.4 \%$, respectively. In order to collect continuous tracking data, we visited the $\mathrm{PhD}$ students' offices to hand out the questionnaires. The online surveys were conducted through a widely used online survey platform in China. We sent out the questionnaire link through the social network

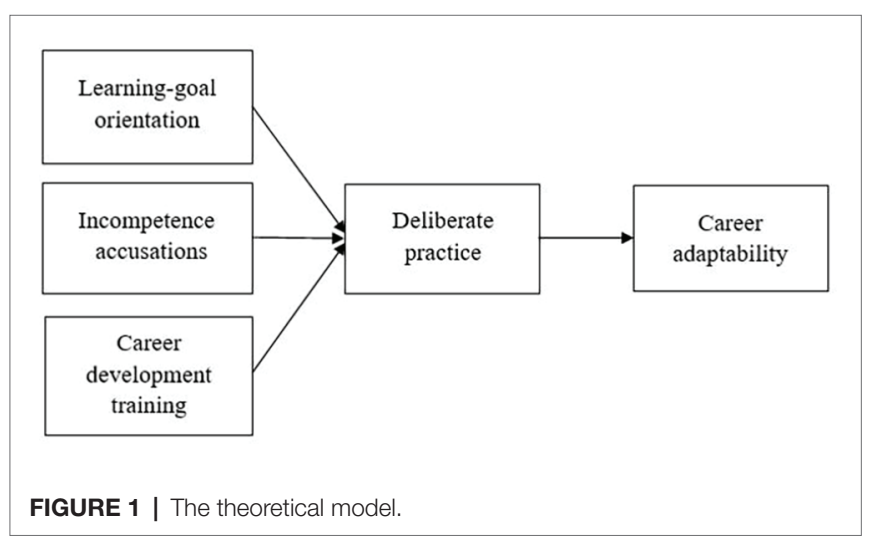

of the research team to ensure reliable sources of data. The respondents of paper-based and online questionnaires were randomly selected in the first wave. To track respondents' answers over time and match three rounds of data, we asked respondents to provide information on their initials and the last two of their student ID number. To encourage $\mathrm{PhD}$ students to participant in this investigation, students who completed each wave of the investigation were compensated with some cash or a small gift. Written informed consent was obtained from all participants in three waves in this study. All participants were assured that the participation was voluntary, and the survey was confidential.

Of the 204 participants who successfully completed the study, $50 \%$ were men and $78.4 \%$ were between 25 and 35 years old $(S D=0.48)$. Most students $(81.9 \%)$ majored in Administrative and Economics. Majority (72.5\%) were in the first and second $\mathrm{PhD}$ year. To avoid any potential effects of pressure, we controlled for whether the students have met requirements for graduation when performing the data analysis. Only $12.7 \%$ have met the basic requirements for graduation during the survey.

\section{Measures}

The surveys were administered in Chinese. All the construct measures in the current study were originally developed in English. Following conventional back translation procedures (Brislin et al., 1973), the English measures were first translated into Chinese by a bilingual $\mathrm{PhD}$ student. Next, the Chinese items were translated back to English by a separate bilingual $\mathrm{PhD}$ student, who was blind to the research hypotheses and the original English items. Then, a bilingual professor of human resource management checked for inconsistencies between the original English language questionnaire and the back-translated one and found only minor discrepancies between these two versions of the measures. Finally, the translators and the professor discussed these discrepancies and made minor changes to the Chinese measures.

\section{Learning Goal Orientation}

We used the eight LGO items from the goal orientation scale developed by Button et al. (1996). All items used five-point Likert-type response scale with anchors from $1=$ strongly disagree to $5=$ strongly agree. Sample items are, "The opportunity to learn new things is important to me," and "I do my best when I am working on a fairly difficult task." The Cronbach's alpha was 0.80 .

\section{Career Development Training}

Following previous research on career training (Verbruggen and Sels, 2008), we used a dummy variable to measure career training participation in the current research. Previous scholars have used dummy variables to measure relevant training and education (e.g., Wilson et al., 2007; Entrialgo and Iglesias, 2016). Therefore, using a dummy variable to measure career training is acceptable in this study. Students who have participated in any career-related programming were coded as one, others were coded as zero. 


\section{Perceived Incompetence Accusations}

We measured perceived incompetence accusations with four items adapted from a scale developed by Chattopadhyay et al. (2010). We amended the items that are originally used in the work context to be more specific to PhD students. Participants were asked to answer on a five-point Likert-type scale ranging from 1 = strongly disagree to $5=$ strongly agree. Example items are, "My PhD supervisor conveyed messages that I needed to perform to a higher standard in academic research," and "I received negative feedback about my research work from my $\mathrm{PhD}$ supervisor." The Cronbach's alpha was 0.70 .

\section{Deliberate Practice}

We used eight DP activities identified in earlier research (Sonnentag and Kleine, 2000; Unger et al., 2009) to measure this variable. $\mathrm{PhD}$ students were asked to indicate retrospectively whether or not they have performed each given activity within the past month $(0=$ no, $1=$ yes $)$. The final score of DP for each respondent was measured using the total number of activities performed by them. Sample activities are, "Attending workshops/training" and "Professional reading." The Cronbach's alpha was 0.71 .

\section{Career Adaptability}

The CAAS China form (Hou et al., 2012) was used to measure CA. Six items each for the subscales. Example items are, "Preparing for the future" (concern), "Sticking up for my beliefs" (control), "Investigating options before making a choice" (curiosity), and "learning new skills" (confidence). Participants were asked to indicate their career adaptabilities with response scale that range from $1=$ not strong to $5=$ strongest. The Cronbach's alpha was 0.94 .

\section{Control Variables}

Prior research has argued that socio-demographic factors such as age, gender, grade, and major have potential influence on students' CA (e.g., Cai et al., 2015; Guan et al., 2017). For example, an empirical study has shown that CA would change over time (Koen et al., 2012). Thus, we controlled for PhD students' age and year in program (YIP). Also, gender might play a role in the formation of CA because recent research suggests that gender differences exist on adaptability-related activities such as career exploration (Han and Rojewski, 2015), we therefore controlled for gender. The participants in this study were from a business university and a university of science and engineering. Because recent research suggests that the required abilities in the fields of Science, Technology, Engineering, and Mathematics are different from the business field (Wang and Degol, 2017), we also controlled for major using dummy variables ( $1=$ business, $0=$ non-business). In addition, previous research has suggested that pressure had influence on the adaptation process and the level of adaptability resources (Hou et al., 2014). Given that the pressure of doctoral students comes mainly from graduation requirements, we controlled for whether participants have met the basic academic requirements using a dummy variable $(1=$ have met the basic academic requirements, $0=$ otherwise).

\section{RESULTS}

\section{Confirmatory Factor Analysis and Descriptive Statistics}

Table 1 presents the descriptive statistics for study variables and controls. Before testing our hypotheses, we conducted confirmatory factor analysis to examine the distinctiveness of the four focal measures in the hypothesized model, namely, LGO, incompetence accusations, DP, and CA. As Pajic et al. (2018) elaborated CFI value greater than 0.85 is adequate. The results in Table 2 indicate that the hypothesized model is acceptable $\left[\chi^{2}(129)=245.00, p<0.001\right.$, CFI $=0.90$, TLI $=0.88$, IFI $=0.90$, and RMSEA $=0.07]$. This measurement model fit the data better than constrained models (see Table 2). These results support discriminant validity of the hypothesized measurement model.

\section{Hypothesis Testing}

We examined the mediation effect with the procedure proposed by Preacher and Hayes (2008). First, we examined the mediating effect with LGO as predictor. The results of Model 2 in Table 3

TABLE 1 | Means, SDs, and correlations among variables.

\begin{tabular}{|c|c|c|c|c|c|c|c|c|c|c|c|c|}
\hline S.no & Variable & $M$ & $S D$ & 1 & 2 & 3 & 4 & 5 & 6 & 7 & 8 & 9 \\
\hline 1. & Gender & 0.50 & 0.50 & & & & & & & & & \\
\hline 2. & Age & 1.91 & 0.48 & $-0.14^{*}$ & & & & & & & & \\
\hline 4. & Year in program & 1.96 & 1.00 & -0.08 & $0.35^{* *}$ & 0.12 & & & & & & \\
\hline 5. & Graduation requirements & 0.13 & 0.33 & 0.09 & -0.02 & 0.06 & $0.30^{* *}$ & & & & & \\
\hline 6. & Learning goal orientation & 3.90 & 0.49 & -0.05 & -0.07 & -0.07 & -0.00 & 0.07 & & & & \\
\hline 9. & Deliberate practice & 4.18 & 2.19 & 0.03 & -0.03 & -0.02 & -0.05 & 0.02 & $0.16^{*}$ & $-0.21^{*}$ & $-0.16^{*}$ & \\
\hline 10. & Career adaptability & 3.78 & 0.52 & -0.13 & 0.09 & 0.02 & $0.16^{*}$ & 0.04 & $0.52^{* *}$ & -0.07 & -0.04 & $0.21^{* *}$ \\
\hline
\end{tabular}

$" p<0.05 ; " p<0.01 . N=204$. 
TABLE 2 | Confirmatory factor analysis results for the measurement models.

\begin{tabular}{|c|c|c|c|c|c|c|c|}
\hline Model & $\chi^{2}$ & $d f$ & $\chi^{2} / d f$ & CFI & TLI & IFI & RMSEA \\
\hline Hypothesized four-factor model & 245.00 & 129 & 1.90 & 0.90 & 0.88 & 0.90 & 0.07 \\
\hline Three-factor model: LGO + SIA, DB, CA & 397.76 & 132 & 3.01 & 0.77 & 0.73 & 0.77 & 0.10 \\
\hline Two-factor model: LGO + SIA, DB + CA & 430.61 & 134 & 3.21 & 0.74 & 0.70 & 0.74 & 0.10 \\
\hline One-factor model: LGO + SIA + DB + CA & 589.97 & 135 & 4.37 & 0.60 & 0.55 & 0.61 & 0.13 \\
\hline
\end{tabular}

$N=204$. LGO, learning goal orientation; SIA, supervisor incompetence accusations; DP, deliberate practice; and CA, career adaptability.

TABLE 3 | Regression results of hierarchical regression analyses.

\begin{tabular}{|c|c|c|c|c|c|c|c|c|c|c|c|c|}
\hline \multirow[b]{2}{*}{ Variable } & \multicolumn{4}{|c|}{ Deliberate practice } & \multicolumn{8}{|c|}{ Career adaptability } \\
\hline & M1 & M2 & M3 & M4 & M5 & M6 & M7 & M8 & M9 & M10 & M11 & M12 \\
\hline Gender & 0.02 & 0.03 & -0.02 & 0.03 & -0.12 & -0.12 & -0.08 & -0.09 & -0.14 & -0.13 & -0.12 & -0.12 \\
\hline Age & -0.00 & 0.01 & 0.00 & 0.00 & 0.03 & 0.03 & 0.06 & 0.06 & 0.03 & 0.03 & 0.03 & 0.03 \\
\hline Major & -0.01 & 0.00 & 0.01 & 0.00 & -0.00 & 0.00 & 0.03 & 0.03 & 0.01 & 0.01 & 0.00 & 0.00 \\
\hline YIP & -0.05 & -0.05 & -0.04 & -0.07 & 0.14 & $0.16^{*}$ & $0.14^{*}$ & $0.15^{*}$ & 0.15 & $0.16^{*}$ & 0.14 & $0.16^{*}$ \\
\hline GR & 0.03 & 0.02 & 0.01 & 0.05 & 0.01 & -0.00 & -0.04 & -0.04 & -0.01 & -0.01 & 0.01 & -0.00 \\
\hline LGO & & $0.16^{*}$ & & & & & $0.52^{* * * *}$ & $0.50^{* * *}$ & & & & \\
\hline SIA & & & $-0.22^{* *}$ & & & & & & -0.11 & -0.06 & & \\
\hline CDT & & & & $-0.17^{*}$ & & & & & & & -0.02 & 0.02 \\
\hline DP & & & & & & $0.23^{* * *}$ & & $0.15^{*}$ & & $0.21^{* *}$ & & $0.23^{* * *}$ \\
\hline $\mathrm{R} 2$ & 0.00 & 0.03 & 0.05 & 0.03 & 0.04 & 0.09 & 0.31 & 0.33 & 0.05 & 0.10 & 0.04 & 0.09 \\
\hline$\Delta \mathrm{R} 2$ & 0.00 & $0.03^{*}$ & $0.04^{* *}$ & $0.03^{*}$ & 0.04 & $0.05^{* *}$ & $0.27^{* * * *}$ & $0.02^{*}$ & 0.01 & $0.04^{* *}$ & 0.00 & $0.05^{* *}$ \\
\hline $\mathrm{F}$ & 0.15 & 0.98 & 1.66 & 1.05 & 1.69 & $3.30^{* *}$ & $14.73^{* * *}$ & $13.82^{* * *}$ & 1.80 & $2.93^{* *}$ & 1.42 & $2.82^{* * *}$ \\
\hline
\end{tabular}

$N=204$. YIP, year in program; GR, graduation requirement; LGO, learning goal orientation; SIA, supervisor incompetence accusations; CDT, career development training; and DP, deliberate practice. ${ }^{*} p<0.05 ; " * 0<0.01 ;{ }^{* * *} p<0.001$.

showed that $\mathrm{PhD}$ students' LGO significantly predicted their DP activities $(\beta=0.16, p<0.05)$, supporting $\mathrm{H} 1$ (path a1 in Figure 2). The results of Model 6 suggested that DP was significantly related to CA $(\beta=0.23, p<0.01)$, supporting H4 (path b in Figure 2). Then, we examined indirect effect by PROCESS analysis (Hayes, 2013) and the bootstrapping results (see Table 4) confirmed the indirect effect of DP on the link of LGO with CA [indirect effect $=0.03$, boot se $=0.02$, $95 \% \mathrm{CI}=(0.01,0.06)$; path $\mathrm{c1}$ in Figure 2]. Overall, H5a was supported.

Second, we examined the mediating effect with SIA as predictor. Hypothesis 2 predicted that SIA is negatively related to DP. The results in Model 3 supported H2 $(\beta=-0.22$, $p<0.01$; path a2 in Figure 2). PROCESS analysis (see Table 4) confirmed the indirect effect of DP on the relationship between SIA and CA [indirect effect $=-0.03$, boot se $=0.02,95 \%$ $\mathrm{CI}=(-0.07,-0.01)$; path $\mathrm{c} 2$ in Figure 2]. Thus, H5b was supported.

Third, we examined the mediating effect with CDT as predictor. As shown in Model 4, CDT had a significant but negative relationship with DP $(\beta=-0.17, p<0.05$; path a3 in Figure 2), contradicting H3. The results of PROCESS analysis indicated that DP had a mediating effect on the relationship between CDT and CA [indirect effect $=-0.05$, boot se $=0.03,95 \% \mathrm{CI}=(-0.11,-0.01)$; path $\mathrm{c} 3$ in Figure 2], thus $\mathrm{H} 5 \mathrm{c}$ was supported. Table 4 presents the results of PROCESS analyses. The overall model and all the results are summarized in Figure 2.

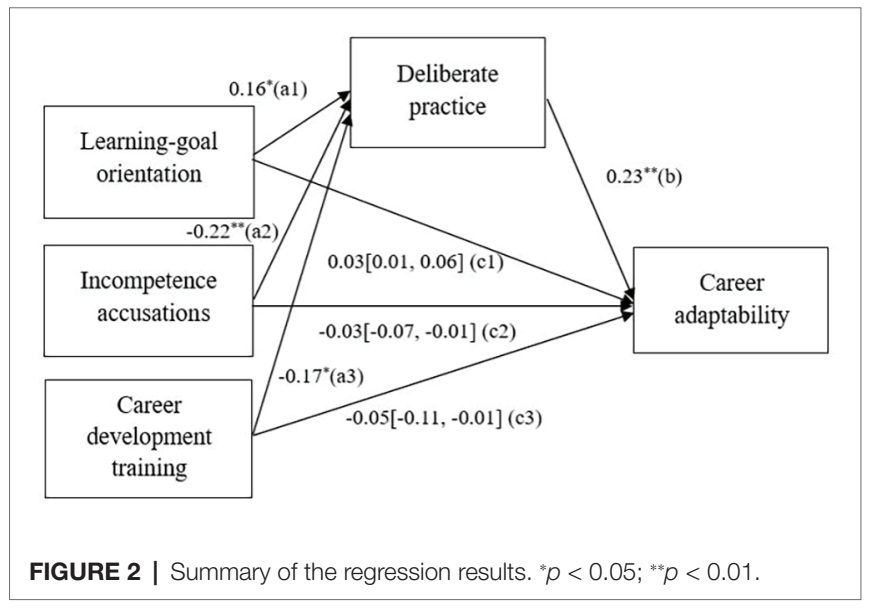

\section{DISCUSSION}

\section{Antecedents of Deliberate Practice}

Scholars have long emphasized the importance of DP in acquiring expert performance (Ericsson et al., 1993; Ericsson and Charness, 1994; Ericsson and Lehmann, 1996). To date, however, very few studies have clarified which factors may facilitate DP. A key contribution of the present study is to demonstrate that an individual difference factor (i.e., LGO) and a supervisor factor (i.e., SIA) as well as an organizational factor (i.e., CDT) serve as three important antecedents of DP and subsequent 
TABLE 4 | Results of PROCESS analyses.

\begin{tabular}{lrcc}
\hline Path & Effect & Boot se & 95\% Cl (lower, upper) \\
\hline $\mathrm{LGO} \rightarrow \mathrm{DB} \rightarrow \mathrm{CA}$ & 0.03 & 0.02 & $(0.01,0.06)$ \\
$\mathrm{SIA} \rightarrow \mathrm{DB} \rightarrow \mathrm{CA}$ & -0.03 & 0.02 & $(-0.07,-0.01)$ \\
$\mathrm{CDT} \rightarrow \mathrm{DB} \rightarrow \mathrm{CA}$ & -0.05 & 0.03 & $(-0.11,-0.01)$
\end{tabular}

$N=204$. LGO, learning goal orientation; SIA, supervisor incompetence accusations; $C D T$, career development training; $D B$, deliberate practice; and $C A$, career adaptability.

CA. Specifically, our results suggested that learning-goal-oriented $\mathrm{PhD}$ students tend to deliberately train themselves. The finding advances knowledge about the discussion of the relationship between inherent dispositions and DP in expertise research (Ericsson and Lehmann, 1996).

Second, our results clearly demonstrated that incompetence accusations from $\mathrm{PhD}$ supervisors reduced $\mathrm{PhD}$ students' engagement in DP. Although researchers require constant criticism to help them improve the quality of their research, it seems that excessive or unfair accusations will reduce the research engagement and impair work performance of young scholars to a certain extent. This is similar to the negative role of abusive leadership in organizational research (e.g., Liu et al., 2012; Sungu et al., 2020).

Interestingly, we found that - contrary to our expectations - CDT was negatively related to DP and CA. A study of Spanish young drivers shows that the under-confident drivers are more interested in taking further training in safe driving than the over-confident ones (Molina et al., 2013). Accordingly, one possible reason why CDT was negatively related to DP and adaptability might be that the participants in this study have strong autonomy so that those who really struggling are participating in training and seeking help and those who with confidence are not involved in training programs. At first glance, one might assume that CDT would be positively associated with DP and CA. However, scholars have long argued that traditional career interventions may not be the best instrument to facilitate good adaptation in the long run due to the rapid change of practices in workplaces (Verbruggen and Sels, 2008). General career interventions such as repeated counseling sessions and assessments may be insufficient in the development of career resources (Koen et al., 2012). In addition, most of the existing CDT is designed for undergraduate students or employees, aiming at facilitating successful schoolto-work or work-to-work transitions (e.g., Koen et al., 2012; Akkermans et al., 2014). The training program that works well for some career pathways (e.g., undergraduate level) may work less well for others such as $\mathrm{PhD}$ level scientific career pathways. Thus, we call for more studies on career training to specially design long-term interventions at a more granular level when promoting self-directed learning and relevant career competence.

\section{The Mediating Role of Deliberate Practice}

The results showed that DP positively predicted CA. This indicates that $\mathrm{PhD}$ students may improve their CA through frequently performing professional-related activities, suggesting that DP serves as important learning behaviors in the adaptation process (Unger et al., 2009) within the academic domain. This finding extends previous knowledge about how CA could be enhanced through specific exercises by demonstrating DP as a key mediating mechanism. This is in line with the viewpoint that CA can be trained and thus it is indeed a learnable competence (Savickas et al., 2009; Koen et al., 2012). In addition, the findings show that DP is an important mediating mechanism linking three predictors (i.e., LGO, SIA, and CDT) with CA. Although existing research has examined extensive antecedents of CA from different perspectives, research on the underlying mechanisms in the form of adaptability competence is still rare. Our research extends the career construction literature by examining the mediating role of DP.

\section{Implications, Limitations, and Suggestions for Future Research}

We deliberately used a sample of Chinese $\mathrm{PhD}$ students instead of the traditional sample of college and high school students when examining the underlying drivers of CA (e.g., Guo et al., 2014; Hou et al., 2014; Tian and Fan, 2014). PhD students are a special group that faces more and more competitive pressure and an increasing risk of mental health issues (Levecque et al., 2017). In our study, we adapted a DP scale specific to $\mathrm{PhD}$ students as many scholars assert the domain-specific nature of DP and found that DP is an effective way for doctoral students to attain adaptability resources. Future studies are encouraged to build on our findings to further test the effectiveness of DP in the career context.

This study also has several implications for practice. Our findings highlight the importance of DP in the academic context. Thus, the drivers of DP should be paid great attention in guiding $\mathrm{PhD}$ students toward increasing their involvement in self-improvement activities. First, the positive effect of LGO on DP calls attention on goal setting in the academic context. It seems valuable for $\mathrm{PhD}$ students and their supervisors to set learning goals toward the academic task and this may increase $\mathrm{PhD}$ students' self-directed learning and lead to better adaptation. Second, our findings indicate that incompetence accusations from $\mathrm{PhD}$ supervisors reduce possible DP. It seems that $\mathrm{PhD}$ supervisors should encourage $\mathrm{PhD}$ students regularly to facilitate them to invest more effort in professional activities. Third, CDT failed to facilitate PhD students' DP of professional activities in the current study. This is particularly noteworthy because it calls attention on rethinking and reform of traditional career training designed for general individuals. In this regard, we call for future research to examine the effectiveness of traditional interventions on $\mathrm{PhD}$ career development, Moreover, given that DP serves as an important driver in the form of $\mathrm{CA}, \mathrm{PhD}$ supervisors could adopt the practice activities we identified in this study (e.g., regular workshop) to help $\mathrm{PhD}$ students initiate $\mathrm{DP}$ and improve professional competence.

Several limitations should be pointed out. First, in the current study, we tested the effect of career-development training on CA using a dummy variable. Although a large 
number of previous studies have adopted this method to measure training participation (e.g., Wilson et al., 2007; Entrialgo and Iglesias, 2016), as suggested by one of the reviewers, we still call for future research to use a scale variable to measure career training (e.g., number of training courses participated in, number of different types of nominal activities endorsed, and extent of engagement with career training). We also call for future study to apply a pre-test, a post-test, and a follow-up test to examine the effectiveness of training programs. Our second limitation is the relatively small sample size. Because our participants were only from two universities in the Southwestern part of China and the majority were from the business field, the generalizability of the findings to other regional and cultural groups and other fields outside of the business context is limited. Different cultural context provides different demands and opportunities to develop and express CA (Savickas and Porfeli, 2012). Thus, future research could make an attempt to apply the research findings to other cultural contexts and disciplines. Third, scholars have argued that self-report survey method may increase common method biases (Podsakoff et al., 2003). Although we collected data in three separate waves, there is still a possibility of common method biases due to the single source of data. Future research is encouraged to use multisource data. Finally, as qualitative research methods would allow participants' lived experience to be explored through in-depth interviews, we suggest that future research conduct qualitative studies to shed additional light on how individuals feel and react when being accused of incompetence. Although our research contributes to the literature on antecedents of CA, it would also be an interesting avenue for further research to further discuss how adaptability affects the mental health of doctoral students.

\section{CONCLUSION}

The present study extended the knowledge about the antecedents of DP and CA. We hope the theoretical implications gained

\section{REFERENCES}

Akkermans, J., Brenninkmeijer, V., Schaufeli, W. B., and Blonk, R. W. B. (2014). It's all about CareerSKILLS: effectiveness of a career development intervention for young employees. Hum. Resour. Manag. 54, 533-551. doi: 10.1002/ hrm.21633

Autin, K. L., Douglass, R. P., Duffy, R. D., England, J. W., and Allan, B. A. (2017). Subjective social status, work volition, and career adaptability: a longitudinal study. J. Vocat. Behav. 99, 1-10. doi: 10.1016/j.jvb.2016.11.007

Baek-Kyoo, J., Sunyoung, P., and Jeong, R. O. (2013). The effects of learning goal orientation, developmental needs awareness, and self-directed learning on career satisfaction in the Korean public sector. Hum. Resour. Dev. Int. 16, 313-329. doi: 10.1080/13678868.2013.782993

Brislin, R. W., Lonner, W. J., and Thorndike, R. M. (1973). Cross-cultural research methods. New York, NY: Wiley.

Brown, S. D., Ryan Krane, N. E., Brecheisen, J., Castelino, P., Budisin, I., Miller, M., et al. (2003). Critical ingredients of career choice interventions: more analyses and new hypotheses. J. Vocat. Behav. 62, 411-428. doi: 10.1016/ S0001-8791(02)00052-0 through this study will encourage future research to investigate how to enhance individuals' CA through targeted practice. Moreover, our focus on indirectly linking the three antecedents (learning-goal orientation, SIA, and CDT) to CA (through DP) also contributes to the research on the mediation role of DP in the expertise literature.

\section{DATA AVAILABILITY STATEMENT}

The raw data supporting the conclusions of this article will be made available by the authors, without undue reservation.

\section{ETHICS STATEMENT}

The studies involving human participants were reviewed and approved by the Academic Ethics Committee of Southwestern University of Finance and Economics. The patients/participants provided their written informed consent to participate in this study. Written informed consent was obtained from the individual(s) for the publication of any potentially identifiable images or data included in this article.

\section{AUTHOR CONTRIBUTIONS}

MM and FY designed the study. MM analyzed the data and drafted the manuscript. FY revised the manuscript and contributed to the section "Discussion." MT coordinated the data collection. All authors contributed to the article and approved the submitted version.

\section{FUNDING}

This research was funded by National Natural Science Foundation of China (NSFC, Project ID: 71502141 and 71902015).

Button, S. B., Mathieu, J. E., and Zajac, D. M. (1996). Goal orientation in organizational research: a conceptual and empirical foundation. Organ. Behav. Hum. Decis. Process. 67, 26-48. doi: 10.1006/obhd.1996.0063

Cai, Z., Guan, Y., Li, H., Shi, W., Guo, K., Liu, Y., et al. (2015). Self-esteem and proactive personality as predictors of future work self and career adaptability: an examination of mediating and moderating processes. J. Vocat. Behav. 86, 86-94. doi: 10.1016/j.jvb.2014.10.004

Charness, N., Tuffiash, M., Krampe, R., Reingold, E., and Vasyukova, E. (2005). The role of deliberate practice in chess expertise. Appl. Cogn. Psychol. 19, 151-165. doi: 10.1002/acp.1106

Chattopadhyay, P., Finn, C., and Ashkanasy, N. (2010). Affective responses to professional dissimilarity: a matter of status. Acad. Manag. J. 53, 808-826. doi: $10.5465 / \mathrm{amj} .2010 .52814603$

Coetzee, M., and Harry, N. (2013). Emotional intelligence as a predictor of employees career adaptability. J. Vocat. Behav. 84, 90-97. doi: 10.1016/j.jvb.2013.09.001

Dunn, T. G., and Shriner, C. (1999). Deliberate practice in teaching: what teachers do for self-improvement. Teach. Teach. Educ. 15, 631-651. doi: 10.1016/S0742-051X(98)00068-7

Dweck, C. S. (1986). Motivational processes affecting learning. Am. Psychol. 41, 1040-1048. doi: 10.1037/0003-066X.41.10.1040 
Entrialgo, M., and Iglesias, V. (2016). The moderating role of entrepreneurship education on the antecedents of entrepreneurial intention. Int. Entrep. Manag. J. 12, 1209-1232. doi: 10.1007/s11365-016-0389-4

Ericsson, A. K. (2006). "The influence of experience and deliberate practice on the development of superior expert performance" in The Cambridge handbook of expertise and expert performance. eds. A. K. Ericsson, N. Charness, P. J. Feltovich and R. B. Hoffman (Cambridge: Cambridge University Press), 685-705.

Ericsson, K. A., and Charness, N. (1994). Expert performance: its structure and acquisition. Am. Psychol. 49, 725-741. doi: 10.1037/0003-066X.49.8.725

Ericsson, K. A., Krampe, R. T., and Tesch-Römer, C. (1993). The role of deliberate practice in the acquisition of expert performance. Psychol. Rev. 100:363. doi: 10.1037/0033-295X.100.3.363

Ericsson, K. A., and Lehmann, A. C. (1996). Expert and exceptional performance: evidence of maximal adaptation to task constraints. Annu. Rev. Psychol. 47, 273-305. doi: 10.1146/annurev.psych.47.1.273

Ericsson, K. A., Roring, R. W., and Nandagopal, K. (2007). Giftedness and evidence for reproducibly superior performance: an account based on the expert performance framework. High Abil. Stud. 18, 3-56. doi: 10.1080/135981 30701350593

Fiori, M., Bollmann, G., and Rossier, J. (2015). Exploring the path through which career adaptability increases job satisfaction and lowers job stress: the role of affect. J. Vocat. Behav. 91, 113-121. doi: 10.1016/j.jvb.2015. 08.010

Ghosh, A., Kessler, M., Heyrman, K., Opelt, B., Carbonelli, M., and Fouad, N. A. (2019). Student veteran career transition readiness, career adaptability, and academic and life satisfaction. Career Dev. Q. 67, 365-371. doi: 10.1002/ cdq.12205

Guan, Y., Dai, X., Gong, Q., Deng, Y., Hou, Y., Dong, Z., et al. (2017). Understanding the trait basis of career adaptability: a two-wave mediation analysis among Chinese university students. J. Vocat. Behav. 101, 32-42. doi: $10.1016 /$ j.jvb.2017.04.004

Guan, Y., Deng, H., Sun, J., Wang, Y., Cai, Z., Ye, L., et al. (2013). Career adaptability, job search self-efficacy and outcomes: a three-wave investigation among Chinese university graduates. J. Vocat. Behav. 83, 561-570. doi: 10.1016/j.jvb.2013.09.003

Guo, Y., Guan, Y., Yang, X., Xu, J., Zhou, X., She, Z., et al. (2014). Career adaptability, calling and the professional competence of social work students in China: a career construction perspective. J. Vocat. Behav. 85, 394-402. doi: $10.1016 /$ j.jvb.2014.09.001

Han, H., and Rojewski, J. W. (2015). Gender-specific models of work-bound Korean adolescents' social supports and career adaptability on subsequent job satisfaction. J. Career Dev. 42, 149-164. doi: 10.1177/0894845314545786

Hansen, J. M., Jackson, A. P., and Pedersen, T. R. (2016). Career development courses and educational outcomes: do career courses make a difference? J. Career Dev. 44, 209-223. doi: 10.1177/0894845316644984

Hayes, A. F. (2013). Introduction to mediation, moderation, and conditional process analysis: A regression-based approach. New York, NY: Guilford Press.

Hirschi, A., Herrmann, A., and Keller, A. C. (2015). Career adaptivity, adaptability, and adapting: a conceptual and empirical investigation. J. Vocat. Behav. 87, 1-10. doi: $10.1016 /$ j.jvb.2014.11.008

Hodges, N. J., Starkes, J. L., and MacMahon, C. (2006). "Expert performance in sport: a cognitive perspective" in The Cambridge handbook of expertise and expert performance. eds. A. K. Ericsson, N. Charness, P. J. Feltovich and R. B. Hoffman (Cambridge: Cambridge University Press), $471-488$.

Hon, A. H. Y., Chan, W. W. H., and Lu, L. (2013). Overcoming work-related stress and promoting employee creativity in hotel industry: the role of task feedback from supervisor. Int. J. Hosp. Manag. 33, 416-424. doi: 10.1016/j. ijhm.2012.11.001

Hou, Z. J., Leung, S. A., Li, X., Li, X., and Xu, H. (2012). Career adapt-abilities scale-China form: construction and initial validation. J. Vocat. Behav. 80, 686-691. doi: 10.1016/j.jvb.2012.01.006

Hou, C., Wu, L., and Liu, Z. (2014). Effect of proactive personality and decisionmaking self-efficacy on career adaptability among Chinese graduates. Soc. Behav. Pers. 42, 903-912. doi: 10.2224/sbp.2014.42.6.903

Johnston, C. S., Luciano, E. C., Maggiori, C., Ruch, W., and Rossier, J. (2013). Validation of the German version of the career adapt-abilities scale and its relation to orientations to happiness and work stress. J. Vocat. Behav. 83, 295-304. doi: 10.1016/j.jvb.2013.06.002
Keith, N., Unger, J. M., Rauch, A., and Frese, M. (2016). Informal learning and entrepreneurial success: a longitudinal study of deliberate practice among small business owners. Appl. Psychol. 65, 515-540. doi: 10.1111/apps.12054

Kinman, G. (2001). Pressure points: a review of research on stressors and strains in UK academics. Educ. Psychol. 21, 473-492. doi: 10.1080/01443410 120090849

Koen, J., Klehe, U. C., and Van Vianen, A. E. M. (2012). Training career adaptability to facilitate a successful school-to-work transition. J. Vocat. Behav. 81, 395-408. doi: 10.1016/j.jvb.2012.10.003

Lan, Y., and Chen, Z. (2020). Transformational leadership, career adaptability, and work behaviors: the moderating role of task variety. Front. Psychol. 10:2922. doi: $10.3389 /$ fpsyg.2019.02922

Levecque, K., Anseel, F., De Beuckelaer, A., Van der Heyden, J., and Gisle, L. (2017). Work organization and mental health problems in $\mathrm{PhD}$ students. Res. Policy 46, 868-879. doi: 10.1016/j.respol.2017.02.008

Liu, D., Liao, H., and Loi, R. (2012). The dark side of leadership: a three-level investigation of the cascading effect of abusive supervision on employee creativity. Acad. Manag. J. 55, 1187-1212. doi: 10.5465/amj.2010.0400

Molina, J. G., Sanmartn, J., and Keskinen, E. (2013). Driver training interests of a Spanish sample of young drivers and its relationship with their selfassessment skills concerning risky driving behavior. Accid. Anal. Prev. 52, 118-124. doi: 10.1016/j.aap.2012.12.035

Negru-Subtirica, O., and Pop, E. I. (2016). Longitudinal links between career adaptability and academic achievement in adolescence. J. Vocat. Behav. 93, 163-170. doi: 10.1016/j.jvb.2016.02.006

Obschonka, M., Hahn, E., and Bajwa, N. U. H. (2018). Personal agency in newly arrived refugees: the role of personality, entrepreneurial cognitions and intentions, and career adaptability. J. Vocat. Behav. 105, 173-184. doi: 10.1016/j.jvb.2018.01.003

Pajic, S., Ulceluse, M., Kismihók, G., Mol, S. T., and den Hartog, D. N. (2018). Antecedents of job search self-efficacy of Syrian refugees in Greece and the Netherlands. J. Vocat. Behav. 105, 159-172. doi: 10.1016/j.jvb.2017. 11.001

Podsakoff, P. M., MacKenzie, S. B., Lee, J. Y., and Podsakoff, N. P. (2003). Common method biases in behavioral research: a critical review of the literature and recommended remedies. J. Appl. Psychol. 88, 879-903. doi: 10.1037/0021-9010.88.5.879

Preacher, K. J., and Hayes, A. F. (2008). Asymptotic and resampling strategies for assessing and comparing indirect effects in multiple mediator models. Behav. Res. Methods 40, 879-891. doi: 10.3758/BRM.40.3.879

Ranabahu, N., and Barrett, M. (2019). Does practice make micro-entrepreneurs perfect? An investigation of expertise acquisition using effectuation and causation. Small Bus. Econ. 54, 1-23. doi: 10.1007/s11187-019-00157-6

Savickas, M. L. (1997). Career adaptability: an integrative construct for lifespan, life-space theory. Career Dev. Q. 45, 247-259. doi: 10.1002/j.2161-0045. 1997.tb00469.x

Savickas, M. L. (2002). "Career construction: a developmental theory of vocational behavior" in Career choice and development. 4th Edn. ed. D. Brown (San Francisco, CA: Jossey-Bass), 255-311.

Savickas, M. L. (2013). "Career construction theory and practice" in Career development and counselling: Putting theory and research into work. 2nd Edn. eds. R. W. Lent and S. D. Brown (Hoboken, New Jersey: John Wiley \& Sons), 147-183.

Savickas, M. L., Nota, L., Rossier, J., Dauwalder, J. P., Duarte, M. E., Guichard, J., et al. (2009). Life designing: a paradigm for career construction in the $21 \mathrm{st}$ century. J. Vocat. Behav. 75, 239-250. doi: 10.1016/j.jvb.2009.04.004

Savickas, M. L., and Porfeli, E. J. (2012). Career adapt-abilities scale: construction, reliability, and measurement equivalence across 13 countries. J. Vocat. Behav. 80, 661-673. doi: 10.1016/j.jvb.2012.01.011

Shin, Y. J., and Lee, J. Y. (2016). Attachment, career-choice pessimism, and intrinsic motivation as predictors of college students' career adaptability. J. Career Dev. 44, 1-16. doi: 10.1177/0894845316653472

Sonnentag, S., and Kleine, B. M. (2000). Deliberate practice at work: a study with insurance agents. J. Occup. Organ. Psychol. 73, 87-102. doi: 10.1348/ 096317900166895

Sonnentag, S., Niessen, C., and Volmmer, J. (2006). "Expertise in software design" in The Cambridge handbook of expertise and expert performance. eds. A. K. Ericsson, N. Charness, P. J. Feltovich and R. R. Hoffman (Cambridge: Cambridge University Press), 373-388. 
Mel et al.

Predictors of Career Adaptability

Sungu, L. J., Mu, E., and Wens, Q. (2020). Goal commitment buffers the negative effects of perceived abusive supervision. Aust. J. Psychol. 154, 273-291. doa: 10.1080/00223980.2019.1709403

Than, Y., and Fan, X. Z. (2014). Adversity quotients, environmental variables and career adaptability in student nurses. J. Vocal. Behave. 85, 251-257. doa: 10.1016/j.jvb.2014.07.006

Tolentino, L. R., Garcia, P. R. J. M., Lu, V. N., Restubog, S. L. D., Bordia, P., and Plewa, C. (2014). Career adaptation: the relation of adaptability to goal orientation, proactive personality, and career optimism. J. Vocal. Behave. 84, 39-48. doa: 10.1016/j.jvb.2013.11.004

Unger, J. M., Keith, N., Hilling, C., Gielnik, M. M., and Free, M. (2009). Deliberate practice among south African small business owners: relationships with education, cognitive ability, knowledge, and success. J. Occup. Organ. Psychol. 82, 21-44. do: 10.1348/096317908X304361

Urbanaviciute, I., Udayar, S., and Rosier, J. (2019). Career adaptability and employee well-being over a two-year period: investigating cross-lagged effects and their boundary conditions. J. Vocal. Behave. 111, 74-90. doa: 10.1016/j.jvb.2018. 10.013

Verbruggen, M., and Gels, L. (2008). Can career self-directedness be improved through counseling? J. Vocal. Behave. 73, 318-327. doe: 10.1016/j.jvb.2008.07.001

Wang, M. -T., and Degol, J. L. (2017). Gender gap in science, technology, engineering, and mathematics (STEM): current knowledge, implications for practice, policy, and future directions. Educ. Psychol. Rev. 29, 119-140. do: 10.1007/s10648-015-9355-x

Wilson, F., Kickul, J., and Marline, D. (2007). Gender, entrepreneurial selfefficacy, and entrepreneurial career intentions: implications for entrepreneurship education [J]. Entrep. Theory Pract. 5, 1042-2587. doa: 10.1111/j.1540-6520.2007. 00179. $\mathrm{x}$

$\mathrm{Xu}, \mathrm{X}$., and Mu, K. (2019). When core self-evaluation leads to career adaptability: effects of ethical leadership and implications for citizenship behavior. J. Psychol. 153, 463-477. do: 10.1080/00223980.2018.1564724

Zacher, H. (2014). Individual difference predictors of change in career adaptability over time. J. Vocat. Behave. 84, 188-198. doi: 10.1016/j.jvb.2014.01.001

Conflict of Interest: The authors declare that the research was conducted in the absence of any commercial or financial relationships that could be construed as a potential conflict of interest.

Copyright (c) 2021 Meir, Yang and Tang. This is an open-access article distributed under the terms of the Creative Commons Attribution License (CC BY). The use, distribution or reproduction in other forums is permitted, provided the original authors) and the copyright owners) are credited and that the original publication in this journal is cited, in accordance with accepted academic practice. No use, distribution or reproduction is permitted which does not comply with these terms.

Frontiers in Psychology | www.frontiersin.org

10

February 2021 | Volume 11 | Article 594791 